\title{
Spectrum of Ocular Surface Squamous Neoplasia - A prospective study
}

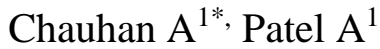 \\ 1. Senior Resident, Department of Opthalmology, Shri C.H.Nagri Eye hospital and research foundation, Ahmedabad.
}

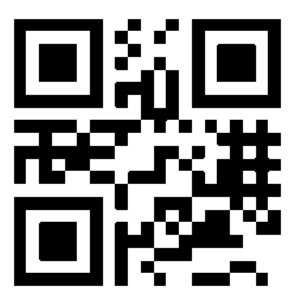

\section{Abstract :}

Background: Prospective Study of Spectrum of Ocular Surface Squamous Neoplasia(OSSN), Its Incidence And Comparison Of Treatment Modality. Material and Methods : The study aim to include 50 eyes of 50 patients with biopsy-proven ocular surface neoplasia at C.H. Nagri Eye Hospital, Ahmedabad. The details of patients were taken regarding Age, Gender, Laterality and Risk factors. Each patient was assessed biomicroscopically for type and complications of ocular surface neoplasia Results: Out of the 50 patients, there were 28 females and 22 males, with mean age being $51.70 \pm 10.84$ Years.OSSN was associated with Sun exposure ( UV) in $42 \%$, no risk factors were found in $48 \%$, while HIV was found in only $4 \%$ patients. All the lesions in study were found in inter palpebral region, more commonly at limbus followed by bulbar conjunctiva with temporal location. No patient had isolated corneal involvement in my study. Gelatinous was commonest morphological type (56\%) followed by leukoplakic (30\%) in my study. On HPE, Invasive carcinoma is more common (42\%). No evidence of MEC, ASCC, PSCC found. There was not even a single case of intra-ocular or orbital invasion. Out of 50 patients, 31 were treated with surgical excision combined with cryotherapy while 19 patients were additionally given MMC postoperatively 4 times/day, 1 week on and 1 week off for 2 months. Two patients $(6.45 \%)$ in Group A were recurred while one patient $(5.26 \%)$ in Group B had recurrence, which was very low as compared to other studies. Conclusion:Surgical excision adjunct with Cryotherapy combined with alcohol abrasion in cases of corneal involvement are the main treatment strategy. Recurrence rates were found higher for more severe grades of OSSN.

Key words: ocular spectrum, UV exposure, Gelatinous, Cryotherapy ,Limbus

*Corresponding Author

Dr.Abhishek Chauhan

E-mail id: chauhan.abhishek.012@gmail.com

Copyright: This is an open-access article distributed under the terms of the Creative Commons Attribution license which permits unrestricted use, distribution, and reproduction in any medium for non-commercial use (Non Commercial, or CC-BY-NC) provided the original author and source are credited.

\section{INTRODUCTION}

The corneal epithelial stem cells located at the basal layer of the limbal epithelia proliferate continuously and give rise to the superficial layer that subsequently differentiate into superficial cells. Regulation of cell growth and metabolism are critical to maintain an intact ocular surface and transparent cornea. ${ }^{1}$ Primary tumors of the conjunctiva and cornea can be grouped into two major categories: congenital and acquired. The acquired lesions are composed of a variety of neoplasms which originate from squamous epithelia, melanocytes, and lymphocyte cells. ${ }^{2-5}$ Tumors of squamous epithelium occupy a large spectrum of lesions, ranging from benign lesions like squamous papilloma, to precancerous lesions which are confined to the surface epithelium (intraepithelial neoplasia or dysplasia, previously known as Bowen's disease).
There are even more invasive squamous cell carcinomas that break through the basement membrane to the underlying substantriapropia of the conjunctiva or corneal stroma. $^{6-8}$ The aim is to study Spectrum of Ocular Surface Squamous Neoplasia (OSSN), Its Incidence and Comparison of Treatment Modality.

\section{MATERIALS AND METHODS}

The study aim to include 50 eyes of 50 patients with biopsy-proven ocular surface neoplasia at C.H. Nagri Eye Hospital, Ahmedabad. The details of patients were taken regarding Age, Gender, Laterality and Risk factors. Each patient was assessed biomicroscopically for type and complications of ocular surface neoplasia.

Exclusion criteria: Cases which are histopathologically ruled out of ocular surface squamous neoplasia. 


\section{Preoperative Assessment}

All patients underwent complete preoperative ocular examination. Detailed history including personal data (name, age, sex, address) was taken. Detailed systemic history including DM, hypertension, ischemic heart disease or hypercholesterolemia was taken.Detailed ophthalmic history of previous intra ocular surgery, ocular disease or trauma was taken. Detailed Ophthalmic examination was done including Best Corrected Visual Acuity (BCVA) measurement with Snellen's visual acuity chart at a distance of 6 meters, Slit Lamp Bio Microscopy, and Intraocular Pressure(IOP) recorded with a GoldmannApplanation Tonometer (Haag Streit, Germany) under topical anesthesia using $0.5 \%$ proparacaine and fluorescein staining of the tear film. The detailed Retinal examination was done with Binocular Indirect Ophthalmoscope using the 20-D lens. Ultrasonography was done to rule out any posterior extension.

\section{Surgical Technique ("No Touch" Technique )}

Prior to surgery, the limits of lesion must be determined by staining. The edges of the area to be excised, marked with a marking pen, using 4-mm margins around the tumor. Any additional foci must be carefully looked for. Peribulbar anesthesia given. Conjunctivalperitomy done. Absolute alcohol socked on an applicator gently applied on the entire corneal component. This causes epithelial cellular devitalization and allows easier release of the tumour cells from bowmen's layer. Corneal dissection done started $2 \mathrm{~mm}$ away from the tumour margin gently towards limbus. Conjunctiva and tenon's capsule removed including 3-4 $\mathrm{mm}$ away from the tumour margin. Whole mass removed. Specimen sent for histopatholgical examination. Saline irrigation done to remove any adherent tumour cells. Cryoprobe applied at the inner margin of remaining part of conjunctiva by lifting away from sclera freezing it up to iceball reaches the size of $4-5 \mathrm{~mm}$. Entire conjunctival margins are treated by double freezing thaw technique. (Limbus+conjunctiva). It includes rapid freezing followed by slow thawing. Primary closure of the conjunctiva was done in case of small defect. But if the defect is large closure was typically carried out by using conjunctival auto graft or Amniotic membrane to cover the exposed sclera.
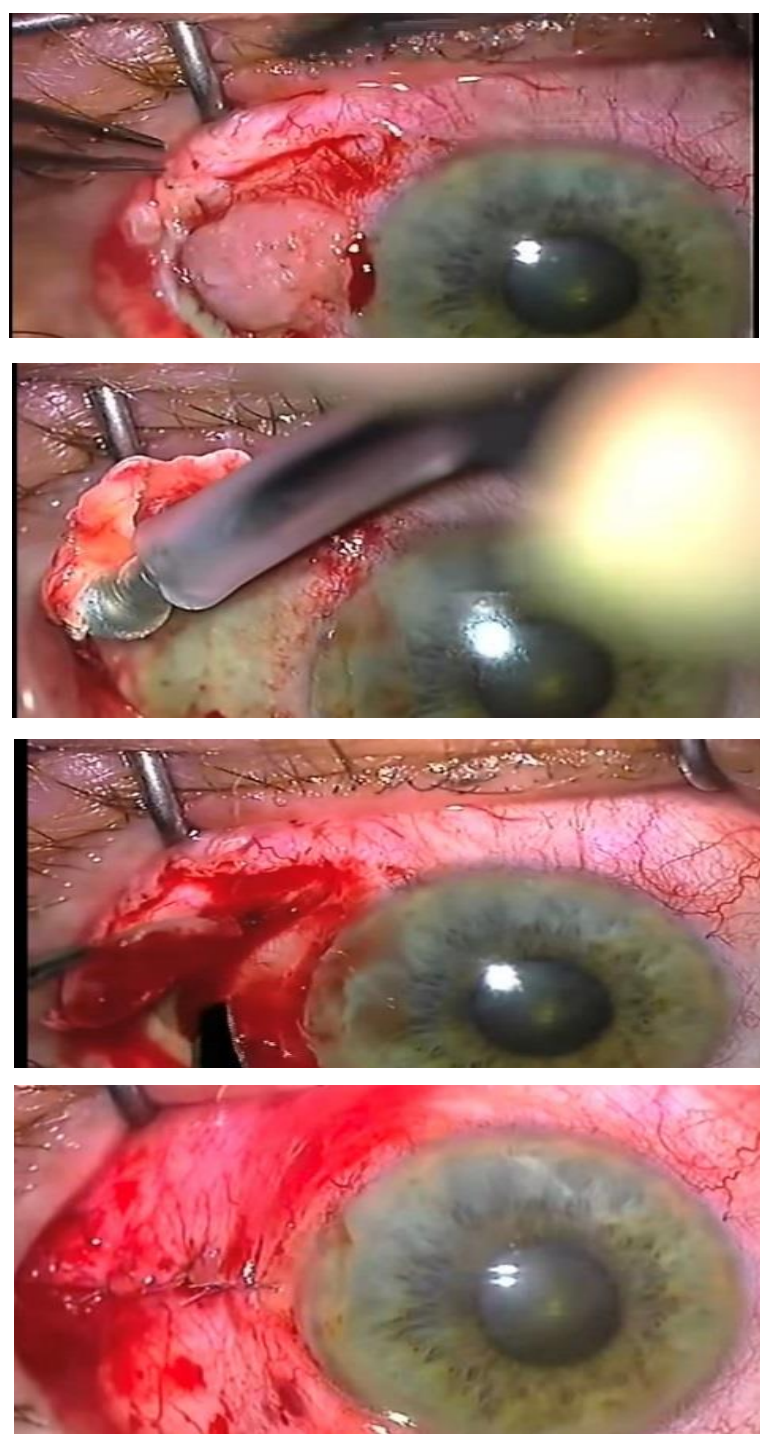

Figure 1: Surgical Technique

\section{Postoperative Assessment}

Postoperative examinations were done at 1 month, 3 months and 6 months. At each postoperative visit: BCVA measurement, IOP measurement, slit lamp biomicroscopy, Fundus examination were done. Patients were examined for any Reccurrence.

\section{RESULTS}

A clinical case series was conducted on 50 eyes of 50 patients who are histhopathologically diagnosed as ocular surface squamous neoplasia at a tertiary care eye hospital. Out of the 50 patients, there were 28 females and 22 males, with mean age being $51.70 \pm 10.84$ Years. 
TABLE 1 Sex Distribution

\begin{tabular}{|l|l|}
\hline OSSN Patients & Tolal(50) \\
\hline Male & $22(44 \%)$ \\
\hline Female & $28(56 \%)$ \\
\hline
\end{tabular}

TABLE 2 Age Distribution

\begin{tabular}{|l|l|}
\hline Age & No \\
\hline$<40$ & $5(10 \%)$ \\
\hline $40-59$ & $32(64 \%)$ \\
\hline $60-79$ & $13(26 \%)$ \\
\hline Total & $\mathbf{5 0}$ \\
\hline
\end{tabular}

TABLE 3 Risk Factor Distribution

\begin{tabular}{|l|l|}
\hline Risk Factor & No. of Patients \\
\hline Sun exposure & $21(42 \%)$ \\
\hline Surface trauma & $3(6 \%)$ \\
\hline HIV identifiable & $2(4 \%)$ \\
\hline $\begin{array}{l}\text { No foctors } \\
\text { risk fact }\end{array}$ \\
\hline
\end{tabular}

TABLE 4 Location Distribution

\begin{tabular}{|l|l|}
\hline Site & $\begin{array}{l}\text { Number } \\
\text { patients }\end{array}$ \\
\hline Temporal limbus & $31(62 \%)$ \\
\hline Nasal limbus & $4(8 \%)$ \\
\hline $\begin{array}{l}\text { Temporal+inferior } \\
\text { limbus }\end{array}$ & $8(16 \%)$ \\
\hline Conjunctiva only & $7(14 \%)$ \\
\hline
\end{tabular}

TABLE 5 Morphological Distribution

\begin{tabular}{|l|l|}
\hline $\begin{array}{l}\text { Morphological } \\
\text { type }\end{array}$ & $\begin{array}{l}\text { Number of } \\
\text { patients }\end{array}$ \\
\hline Gelatinous Nodular & $29(56 \%)$ \\
\hline $\begin{array}{l}\text { Leukoplakic } \\
\text { Nodular }\end{array}$ & $15(30 \%)$ \\
\hline Papilliform & $3(6 \%)$ \\
\hline Diffuse Infiltrative & $3(6 \%)$ \\
\hline
\end{tabular}

TABLE 6 Treatment Modality

\begin{tabular}{|l|l|}
\hline $\begin{array}{l}\text { Treatment } \\
\text { modality }\end{array}$ & No. of Patients \\
\hline $\begin{array}{l}\text { Excision+ } \\
\text { Cryotherapy }\end{array}$ & 31 \\
\hline $\begin{array}{l}\text { Excision+ } \\
\text { Cryotherapy+ } \\
\text { Mitomycin-c } \\
\text { eyedrop }\end{array}$ & 19 \\
\hline
\end{tabular}

TABLE 7 Histopathological Distribution

\begin{tabular}{|l|l|}
\hline HP grading & No. of Patients \\
\hline Papilloma & $2(4 \%)$ \\
\hline CIN grade- 1 & $8(16 \%)$ \\
\hline CIN grade-2 & $8(16 \%)$ \\
\hline CIN grade-3 & $13(26 \%)$ \\
\hline Invasive SCC & $19(42 \%)$ \\
\hline
\end{tabular}

TABLE 8 Comparison of Treatment Modalities

Group A: Excision+Cryo therapy

Group B: Excision+Cryo therapy+ Post op. Mmc eye drop

\begin{tabular}{|l|c|c|c|}
\hline & $\begin{array}{l}\text { Recurrence } \\
\text { Present }\end{array}$ & $\begin{array}{l}\text { Recurrence } \\
\text { Absent }\end{array}$ & Total \\
\hline Group A & 2 & 29 & 31 \\
\hline Group B & 1 & 18 & 19 \\
\hline Total & 3 & 47 & 50 \\
\hline
\end{tabular}

* No significance of difference was found in between this two groups. (p>0.05) [chi-square test]

\section{DISCUSSION}

OSSN is a slow growing tumor; however in neglected cases it can invade the globe and orbit. It has a potential for recurrence after treatment. Out of the 50 patients, there were 28 females and 22 males, with mean age being $51.70 \pm 10.84$ Years. OSSN occurs predominantly in the elderly patient, more in male as compared to female. ${ }^{9}$ The average age of occurrence of $\mathrm{OSSN}^{10}$ as 56 years with male predominance. In my study OSSN was associated with Sun exposure (UV) in $42 \%$, no risk factors were found in $48 \%$, while HIV was found in only $4 \%$ patients. All the lesions in my study were found in interpalpebral region, more commonly at limbus followed by bulbar conjunctiva with temporal location. No patient had isolated corneal involvement in my study. Among the different morphological types, gelatinous was common $(56 \%)$ followed by leukoplakic $(30 \%)$ in my study. On HPE, Invasive carcinoma is more common (42\%). No evidence of MEC, ASCC, PSCC found. There was not even a single case of intraocular or orbital invasion. Out of 50 patients, 31 were treated with surgical excision combined with cryotherapy while 19 patients were additionally given MMC postoperatively 4 times/day, 1 week on and 1 week off for 2 months. Two patients $(6.45 \%)$ in Group A were recurred while one patient $(5.26 \%)$ in Group B had recurrence, which was very low as compared to other studies.

\section{Study Limitations}

- Patients were followed up for short period of time (6 months).

- PCR (Polymerase chain reaction) could not be included in the study as a diagnostic tool to detect HPV due to its high cost. 
- Interferons could not be included in the study as a treatment modality

\section{CONCLUSION} due to its high cost.

Ocular Surface Squamous Neoplasia is a spectrum of diseases ranging from simple Dysplasia to Invasive carcinoma. This lesion is considered a low grade malignancy, but its invasive counterpart can spread to the globe or orbit. It is the most common ocular surface tumor. OSSN was commonly seen in elderly female patient (56\%). The main risk factor was UV-B exposure (42\%). However we couldn't find any risk factors in many patients. This might happened because it was not possible to use certain higher diagnostic tools in lower socio-economical patients. Most of the patients presented without any symptoms. Clinically, these tumors most commonly arise in the interpalpebral area, particularly at the limbal region in the temporal quadrant. Morphologically Gelatinous (56\%) and leukoplakic (30\%) were the most common types to be present. In clinical practice, OSSN is generally evaluated by Histopathological examination. invasive forms (42\%)were commonly seen, this might be related to ignorance of the patient. Surgical excision adjunct with Cryotherapy combined with alcohol abrasion in cases of corneal involvement are the main treatment strategy. Recurrence rates were found higher for more severe grades of OSSN. Topical chemotherapy such as MMC may reduce the recurrence rate, but incomplete excision still remains the main reason for recurrence. Invasive disease may cause intraocular or orbital involvement with eye loss. Recurrence after initial treatment is variable and warrants life-long follow-up in all case of OSSN.

Conflicts of interest: Declared, authors have no conflict of interest.

Funding/Financial support: None

\section{REFERENCES}

1. Lee GA, Hirst LW. Ocular surface squamous neoplasia. SurvOphthalmol 1995;39:429-50.

2. Pizzarello LD, Jakobiec FA. Bowen's disease of the conjunctiva: a misomer. In: Jakobiec FA, editor. Ocular adnexaltumors. Birmingham, AL: Aesculapius; 1978. p.
$553-71$.

3. Karcioglu ZA, Wagoner MD.Demographics, etiology, and behaviorof conjunctival squamous cell carcinoma in the 21st century. Ophthalmology 2009;116:2045-6.

4. Roy A, Rath S, Das S, Vemuganti GK, Parulkar G. Penetrating sclerokeratoplasty in massive recurrent invasive squamous cellcarcinoma. OphthalPlastReconstrSurg 2011;27:39-41.

5. Panda A, Sharma N, Sen S. Massive corneal and conjunctival squamous cell carcinoma. Ophthalmic Surg Lasers 2000;31:71-2.

6. Shields JA, Shields CL. Eyelid, conjunctival and orbital tumors. $2^{\text {nd }} e d$. An atlas and text book. Philadelphia: LWW press; 2008 .

7. Templeton AC. Tumors of the eye and adnexa in Africans in Uganda.

Cancer 1967;20:1689-98.

8. Lee GA, Hirst LW. Incidence of ocular surface ep-ithelial dysplasia in metropolitan Brisbane. A 10-year survey. Arch Ophthalmol1992;119:525-7.

9. Sun EC, Fears TR, Goedert JJ Epidemiology of squamous cellconjunctival cancer. Cancer Epidemiol Biomarkers Prev 1997;6:73-7.

10. Kao AA, Galor A, Karp CL, Abdelaziz A, Feuer WJ, DubovySR.Clinicopathologic correlation of ocular surface squamous neoplasms at Bascom Palmer Eye Institute: 2001-2010. Ophthalmology2012;119:17736. 